\title{
PROMOTING THE EFFECT OF THE QING DYNASTY IMPERIAL GARDEN ARCHITECTURAL COMPONENT LIBRARY ON THE DIGITALIZATION OF CULTURAL HERITAGE
}

\author{
Jindan Cui a , Junsong Zhang a , Jiujun Zhang a \\ a Beijing Re-Yuanmingyuan Company Limited, No.41 Shangdi West Road, Haidian District, Beijing, P.R.China - (cuijindan, \\ zhangjunsong, zhangjiujun)@thid.cn
}

KEY WORDS: Component Library, Virtual Reconstruction, Heritage Protection, Yuanmingyuan

\begin{abstract}
:
With the development of computer technology and practical verification, digital virtual technology has matured and is increasingly being widely applied to cultural heritage protection and research. With this advancement in technology, there is pressing need to simplify heritage-related puzzles. Thus the main question that has increasingly become the most central and fundamental problem in heritage digitalization work is how to choose the "proper technology" that provides support directly, accurately and rapidly for the research, protection and exchange of cultural heritage. Based on the principles of "authenticity" and "completeness" found in the Venice Charter in regards to dealing with cultural heritage; this paper proposes the concept of the component library which facilitates the improvement and efficiency of virtual reconstruction, provides a visual discussion platform for cultural heritage protection, virtual scene construction, accuracy assessment, and multi-space-time exhibition; thereby implementing the spirit of tolerance and respect found in the Nara Document on Authenticity. The paper further aims to illustrate the significance of the Qing dynasty imperial garden architectural component library for cultural heritage study and protection, the principles for virtual library construction, use and maintenance of the library, and classification approaches, and also provide some suggestions about making high quality $3 \mathrm{D}$ models and effective means for database integration.
\end{abstract}

\section{INTRODUCTION}

With the establishment of the open scientific research platform "Re-relic" 1 in 2009 , the strengths of digital virtualization technology has become self-evident in cultural heritage protection and research. The "Re-Yuanmingyuan" project, part of the "Re-relic" platform, has successfully developed a set of relatively mature virtual reconstruction theoretical systems, which is based on architectural history, combines archaeological investigation and makes use of modern digital technology and networks to complete reconstruction exhibitions. Besides the 4D spatial-temporal evolution system that creates different information to make expressions in multi-space-and-time, the "Re-Yuanmingyuan" project also introduces the concept of "digital fabrication". In accordance with this concept, the architectural 3D model includes both the inner and outer space of a building; digital model construction and dismantling, which are decomposed to each independent component; and the model is established under the authentic technology and process in proper space and time, such as the mortice and tenon connection, roof drainage simulation, and rockery stacking (Yan He, 2014a), to fully emphasize the importance of the unit components and the construction process in the re-construction of "cultural heritage".

Through continuous exploration and research, this paper is devoted to finding an appropriate optimization method, so as to shorten the working cycle of the restoration design and scene fabrication, to bring in more efficient exhibition of the

\footnotetext{
${ }^{1}$ Based on early research and the application of information technology, a system called "Re-relic" was constructed with the purpose of supporting research, archaeological excavation, heritage conservation, heritage management and public participation. This was achieved through the collection of heritage information, development of specific databases, and setting up digital reproduction models and comprehensive heritage information systems. "Re-Yuanmingyuan" was the first outcome of the "Re-relic" platform.
}

restoration research results, and to illustrate the concept of "digital construction" in a clearer way. Within such parameters, the QDIGACL (Qing dynasty imperial garden architectural component library) has arrived at the correct moment and can be explored further.

\section{SIGNIFICANCE OF INTRODUCING THE COMPONENT LIBRARY}

\subsection{Improve digitalization efficiency}

The traditional virtual reconstruction process targeted at each research object is to make a particular restoration design from the most basic component to the concrete structure and layout, use AutoCAD as a platform to draft design drawings, and carry out a one-to-one $3 \mathrm{D}$ scene fabrication after the fundamental research is completed. This process consumes a lot of materials, labor force and time due to low digitalization efficiency. By comparison, the QDIGACL breaks this mode by setting the smallest component as the fundamental research object, fabricates 3D model as per certain "rules" and "codes", inputs such attribute information as research files and CAD design drawings into the library, and allows for direct taking of 3D models from the library. In this way, it realizes the integration of traditional study with virtual reconstruction, avoids repeated restoration design and scene fabrication, and greatly improves the digitalization efficiency.

\subsection{Realizing visual comparative study}

It is obvious that the QDIGACL is not a pure literal explanation but a visual 3D model database, which can help to broaden the thoughts and perspectives of researchers. This kind of research mode, supported by library construction, not only endows the component with spatial attributes but also realizes horizontal connections among buildings. Through the component library, 
researchers are able to compare the use of the same components in different buildings or the change of the same component or component sets in the same building in different periods of time. In the future, as the component library is no longer limited to the application to Qing dynasty imperial garden architecture, and includes more data information about various civil buildings and gardens of different historical periods (such as the Song and Ming dynasty), it will help to carry out a richer study about the evolution of Chinese ancient buildings.

\subsection{Providing testing mechanisms}

The component 3D models in the QDIGACL are standard pieces fabricated according to the Gongcheng Zuofa Zeli ${ }^{2}$, thus they can be used as the testing mechanism for component change. During restoration, researchers sometimes may find there are differences between the authentic historical information and regulations. In such cases, researchers could compare the changed historical components with the standard pieces in the component library so as to further understand the causes for these differences, K.E. Larsen (1994) suggests that one make "efforts to update authenticity assessments in light of changing values and circumstances" (K.E. Larsen, 1994) thus helping to unveil the historical truth.

\section{ESTABLISHMENT OF THE QDIGACL}

\subsection{Feasibility of establishing the QDIGACL}

Traditional buildings at first seem to be especially complicated, but during the Qing dynasty, an official system was established to define and classify official buildings, especially its architectural form, construction method, building material, technology and regulations, thereby forming a relatively unified style and characterization for official buildings of the Qing dynasty with two features: formalization, which means that detailed rules and specifications were established for the dimensions of buildings of different sizes and uses; and standardization, which means that identical components from buildings of similar size were classified so that they could be used in any building within the same level and specification. Therefore the engineering department of the Qing dynasty published the corresponding architectural standard Gongcheng Zuofa Zeli to specify building measurement systems to ensure that official buildings of the Qing dynasty observed fabrication rules, and different components maintained proportional relationships. This makes it possible that during the construction of official buildings in the Qing dynasty, the components can be prefabricated in advance according to architectural modules in order to enhance the universality of the components. Since Qing dynasty imperial garden architecture is one part of the official buildings, the component restoration design obtains a solid basis, which proves the feasibility of establishing a component library.

\subsection{Three fundamental principles for a component library}

1 The establishment of the component library should be universally applicable. The QDIGACL is not being established for a particular project; instead it actually includes a diversity of standardized 3D model data information so that each virtual reconstruction object can directly or indirectly output an ideal 3D model from the component library to minimize the time for scene construction. This is the first and most fundamental rule for the establishment of the component library.

2 The component library should follow the principle of authenticity. Even though the QDIGACL uses the Gongcheng Zuofa Zeli as its blueprint and previous restoration research as its support, it still has a wide application scope. Thus it is necessary to take into consideration that the restoration object is affected by many other factors, such as a craftsman's design and construction condition restrictions during the construction process and thus some differences may exist. It reminds us that we cannot blindly simplify the restoration design and scene fabrication process, but should reasonably make use of the applicability of the component library. When improving virtual reconstruction efficiency, we should meet the challenges and differences of the object and ensure the authenticity of the re-production. This is the basic rule for cultural heritage protection and the component library use.

3 Component library maintenance should allow for expansion. Although during the scene fabrication process some objects cannot be directly found in the component library, it does not mean the component library is no longer meaningful. The 3D model data information included in the component library supports dynamic optimization and updating. When there is no matching component mode, we can find the component of similar attributes in the component library, and using this component to produce an applicable new component in accordance with the restoration design by adjusting the dimensions and materials of the component mode in 3D MAX. We can also expand the QDIGACL to include ancient architectural garden and landscape component library applicable to more objects through incessant research and accumulation. The Yingzao Fashi of the Song dynasty and the Yongle Canon of the Ming dynasty are two additional resources that can make it feasible for transplanting the component library.

\subsection{Composition of the QDIGACL}

In accordance with previous scene fabrication experience, the 3D model and the target map do not corresponding to each other one to one; in fact they may actually correspond one to several or several to several. If all possible permutations and combinations are inputted into the component library, high data redundancy will occur and erroneous matching may be produced thus bringing about misunderstanding and confusion for researchers. Therefore, the QDIGACL is divided into two parts: the 3D model library and the map library. To facilitate retrieval and actualization, continual comparative research and correction and maintenance of the components is necessary to further classify and describe the 3D model and map library.

In accordance with the restoration design steps and virtual scene fabrication process, the 3D model library is divided into two categories: the general drawing element and the single building. The general drawing element includes not only the rockery, pond, and plant configuration as part of the landscape architecture but also the wood and brick work in landscape architecture such as walls, doors, roads and bridges. The fabrication is mainly based on the surveying and mapping of buildings and landscape relics of the same time period, in combination with archaeological investigation records and literature files.

Just as its name indicates, the single building can be divided into four parts under the basic composition of a typical Qing dynasty imperial garden architecture: terrace, wooden structure, barrier and roof (figure 1). A special modularized standard component 3D model is fabricated for each part in accordance with the Gongcheng Zuofa Zeli issued by the engineering department in the Qing dynasty.

\footnotetext{
${ }^{2}$ Qing dynasty Architectural Methods Regulation
} 


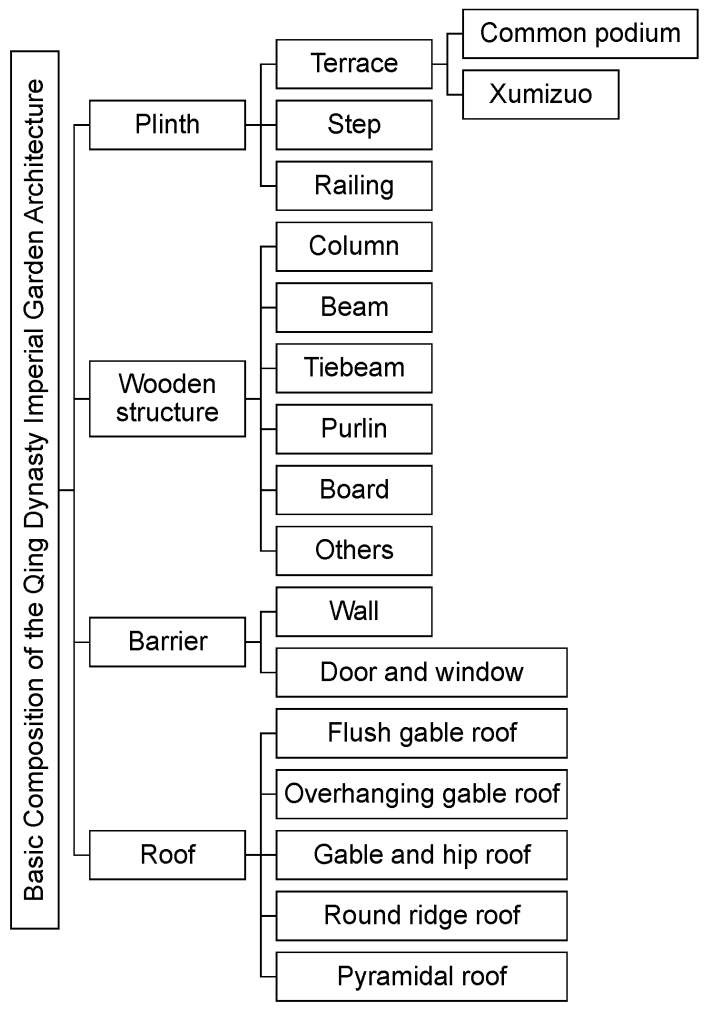

Figure 1. Basic Composition of Qing Dynasty Imperial Garden Architecture

On the basis of the 3D model library classification, the map library grades the use frequency (table 1). The target is to plan the map production and maintenance priority so as to ensure the map library can play its due function in cooperating with the $3 \mathrm{D}$ model library. Meanwhile it can also facilitate the summarization and study about the appearance and style of Qing dynasty imperial garden architecture, such as color paintings.

\begin{tabular}{|c|c|c|c|c|}
\hline No. & $\begin{array}{l}\text { Map } \\
\text { Type }\end{array}$ & $\begin{array}{c}\text { Classifica } \\
\text { tion II } \\
\end{array}$ & Classification III & $\begin{array}{r}\text { Use Frequency } \\
(\star \sim \star \star \star \star \star)\end{array}$ \\
\hline \multirow{10}{*}{1} & \multirow{10}{*}{ Floor } & \multirow{4}{*}{$\begin{array}{c}01 \\
\text { Indoor } \\
\text { laying }\end{array}$} & 01Jindun Brick & $\star$ \\
\hline & & & $\begin{array}{l}02 \text { Flower Brick (wall } \\
\text { engraving) }\end{array}$ & $\star \star$ \\
\hline & & & $\begin{array}{l}03 \text { Square bricks of two, } \\
\text { four and seven feet }\end{array}$ & $\star \star \star$ \\
\hline & & & 04 City wall brick & $\star \star$ \\
\hline & & \multirow{4}{*}{$\begin{array}{c}02 \\
\text { Pavement }\end{array}$} & $\begin{array}{l}01 \text { One row of square } \\
\text { bricks (set) }\end{array}$ & $\star \star \star \star$ \\
\hline & & & $\begin{array}{l}02 \text { Three rows of square } \\
\text { bricks (set) }\end{array}$ & $\star \star \star \star$ \\
\hline & & & 03 Crack pattern & $\star \star$ \\
\hline & & & 04 Special style (set) & $\star$ \\
\hline & & \multirow{2}{*}{$\begin{array}{c}03 \\
\text { Apron }\end{array}$} & $\begin{array}{l}01 \text { Substrate brick and } \\
\text { surface brick (set) }\end{array}$ & $\star \star \star$ \\
\hline & & & $\begin{array}{l}02 \text { Substrate brick and } \\
\text { pebble (set) }\end{array}$ & $\star \star \star \star \star$ \\
\hline
\end{tabular}

Table 1. Example of Classification List in Map Library

In accordance with the principle of authenticity, the whole map library incorporates real pictures plus special processing in order to accurately display material features, pattern details and color information of the virtual building and garden landscape.

\section{PROVIDING AN EFFICIENT AND AUTHENTIC MODEL COMPONENT LIBRARY}

\subsection{Saving resources and fluid operation}

After the restoration and modeling of dozens of scenic spots in the "Re-Yuanmingyuan" Project in 3D MAX, we find that there is an exponential increase of 3D model faces which may cause scene display's to be blocked and even cause the program to crash because there are too many faces. Therefore it is suggested to reduce the number of faces in the fabrication of each 3D model component. This approach can be used to control the number of faces for the entire scene.

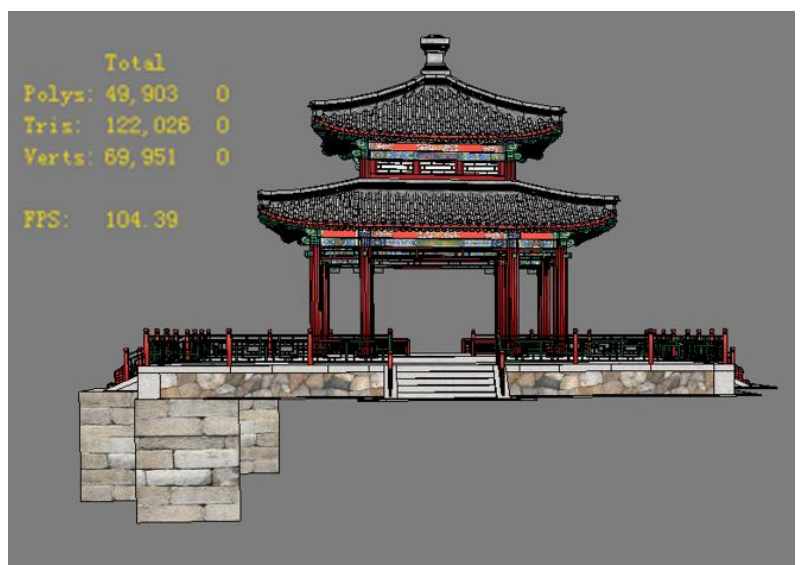

Figure 2. Previous 3D Model of Liuxiangzhu Pavilion

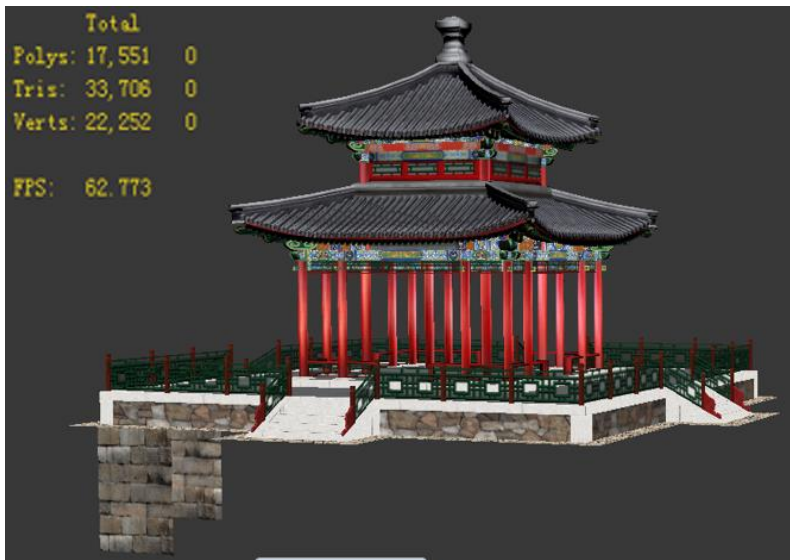

Figure 3. Current 3D Model of Liuxiangzhu Pavilion

When analyzing Figure 2 and Figure 3, we can find the differences between the two 3D models. The previous 3D model had almost 120,000 faces while the new 3D model constructed with a component library had only 30,000 faces. In this way, the 3D model occupies fewer resources while the scene operation efficiency is higher and the effect is more fluid.

\subsection{Map integration, maintenance and upgrade}

The 3D model map also has its own independent use. For example, each map (128x128) is fabricated for each component such as tiling, eave tile, edge, rafter and so on, on the roof. Such practices bring a much clearer effect, but it also may reduce the engine speed, and for frequent mapping request, it would 
increase the computation volume. Especially in scene operations, the components will frequently appear, and the extremely high frequency requests will lead to a delay or even a system crash. In such cases, the usual practice is to reduce the scene scale to divide the relatively concentrated scenic spots into several parts for display. We change the way of mapping by incorporating several component sets into a bigger map (1024x1024) which can contain several or even dozens of different component maps that are used by more than ten different 3D models at one time through engine requests. The effective integration of maps helps to reduce the frequency requests and improves the display efficiency (figure 4).
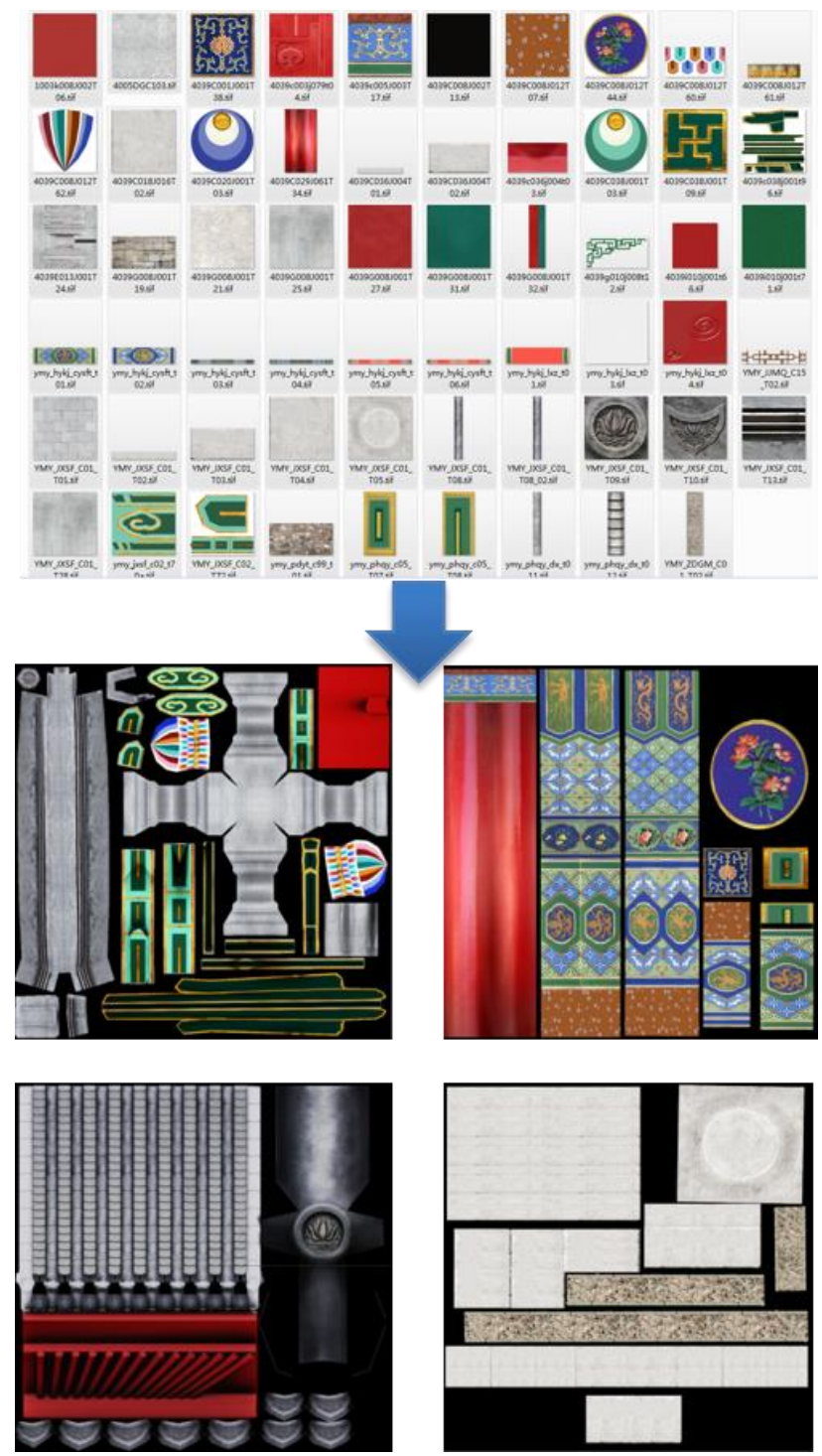

Figure 4. Map Integration

Likewise, the number of material balls also affects the frequency of map requests. A material ball is a material management set composed of several maps. In the engine, the maps exist in the form of a material ball in order to facilitate map management and enhance the lighting and shading effect of the maps. Effective map integration is equal to effective integration of a material ball.

Figure 5 and 6 compare the number of material balls found in the digital reconstruction of Liuxiangzhu Pavilion in Yuanmingyuan.
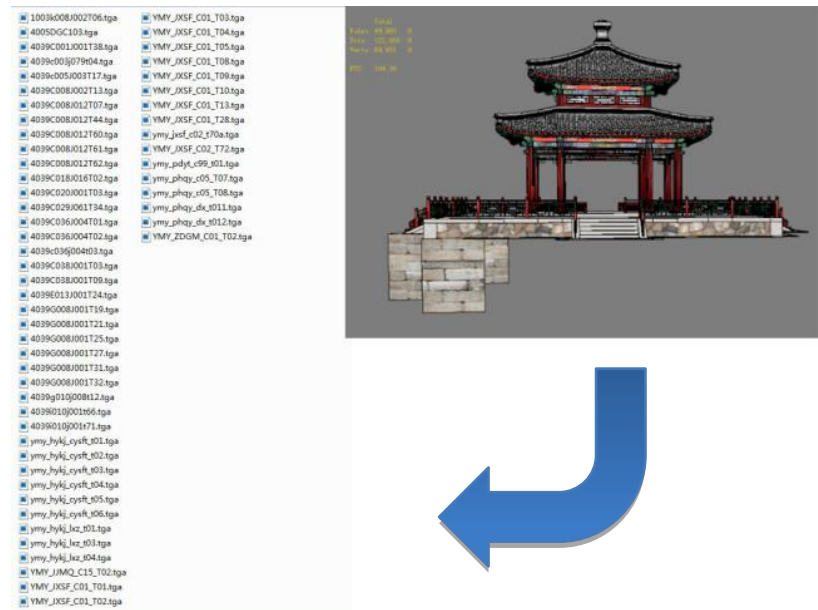

Figure 5. Map of the Previous Liuxiangzhu Pavilion 3D Model
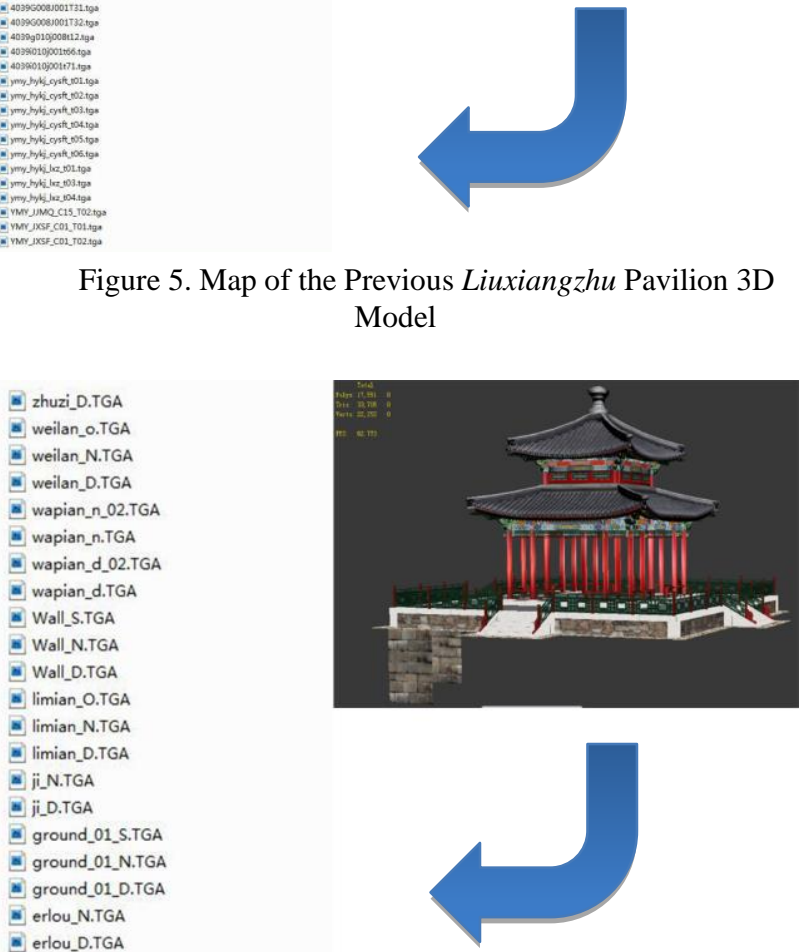

Figure 6. Map of the Present Liuxiangzhu Pavilion 3D Model

The pavilion that was originally constructed had 59 tga maps (figure 5) where as the reconstructed model using the component library had only 28 tga maps (figure 6).

Effective map integration can not only improve display efficiency, but can also improve material retrieval as well as corresponding corrections and maintenance.

\subsection{Vivid lighting and shading and rich details}

The 3D model from the QDIGACL is constructed using the UDK engine, and applies the latest display engine standard, which can provide vivid display effects. Normal baking technology can help to produce highly precise details in the $3 \mathrm{D}$ model.
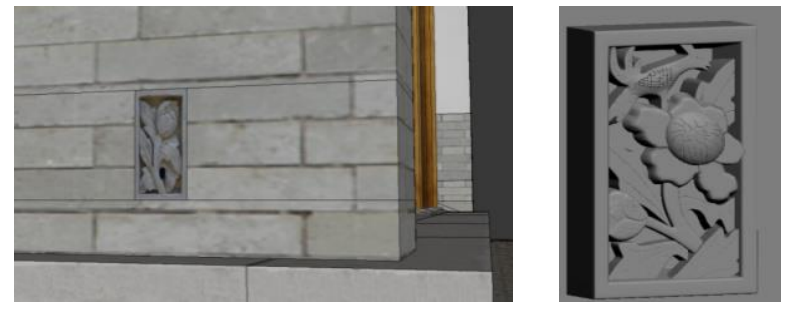

Figure 7. Transom 3D Model

Take the pattern on the transom 3D model as an example (figure 
7). The figure on the left shows a simple map, while the figure on the right is a complicated high-precision 3D model with millions of faces. Baking technology is used to obtain a normal blue map, which fulfills its function together with the original map (figure 8). In this way, high-quality display effects can be achieved in the UDK engine using fewer resources.
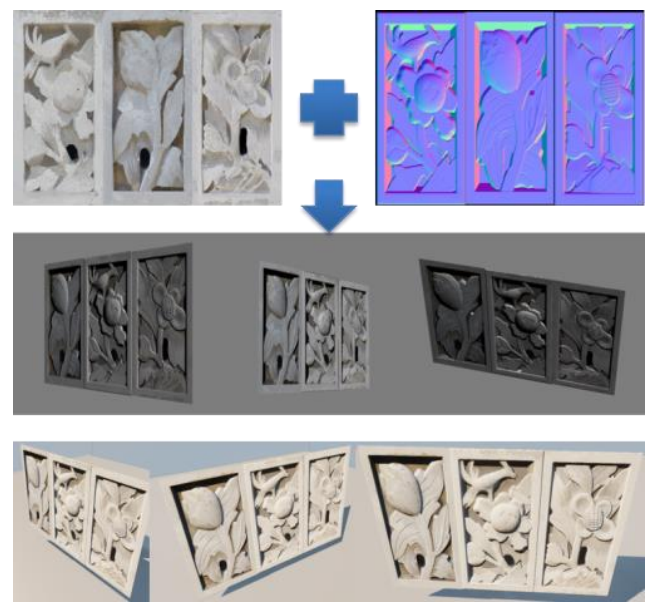

Figure 8. 3D Model Baking

\section{ESTABLISHMENT OF THE COMPONENT LIBRARY SYSTEM}

The major objective of establishing the component library on the basis of relational databases and $3 \mathrm{D}$ platforms is to realize synchronous management and unified storage of the $3 \mathrm{D}$ information as well as the corresponding attribute information and component organization structure of the Qing dynasty imperial garden architecture and landscape element components.

\subsection{Logic relation of the component library}

In regards to Qing dynasty imperial garden architecture, in the database logic design, there are three logical levels as per organizational hierarchy relationship: building, part and component. Each logical level can be added to its corresponding attributes at any time. The real object and its attributes are linked with a unique identifier. In logical structures, each building is composed of several parts while each part is composed of several components; the smallest is also the most fundamental unit (figure 9). When the object is changed to a landscape element, the logic remains the same.

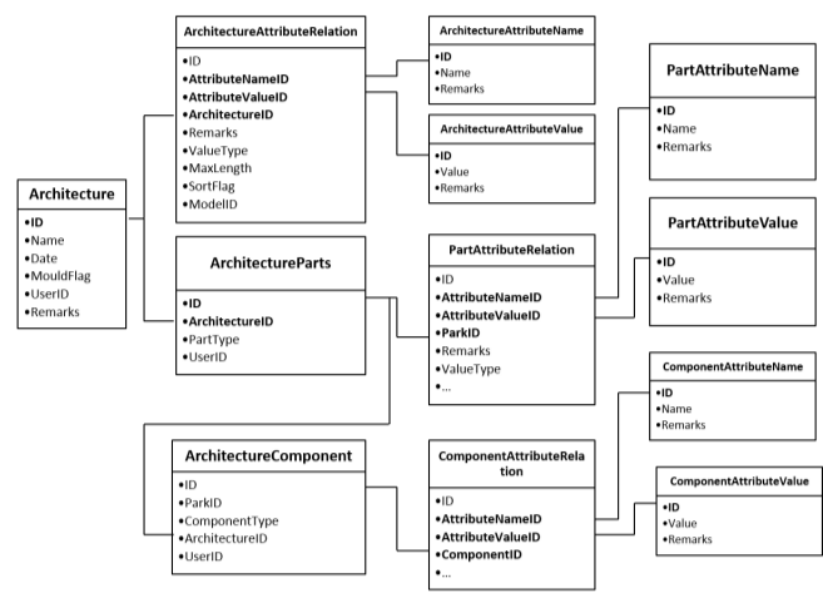

Figure 9. Logical Structure of a Database
5.2 Relationship between 3D model information and attribute information of components

In the component library, the object exists as a component. The objects of the building or landscape level and part level are linked through the 3D model object information in the component library as well as the organization structure information in the related database. They can be directly or indirectly formed with several components as per organizational relationship.

The attribute information of the buildings or landscape, parts and components have three independent attribute information databases for information storage and management. It can be displayed in several formats: words, values, pictures, files and videos. All such attribute information is managed synchronously through the unique identifier of the three levels of the objects: building or landscape, part and component.

\subsection{Attribute information template}

The role of the attribute information template is to further standardize and unify the attributes of the objects at different levels of similar buildings or landscapes, and reduce the repeated input of such attributes of the objects at three levels in order to improve information input efficiency.

\subsection{Inputting information into the client}

The information input client-side program used in combination with the component library is developed and completed on the 3D GIS platform. It can realize such services, maintenance and updating functions such as a 360 degree view of the Qing dynasty imperial garden architecture and landscape element components of the 3D models; rendering and displaying, in different categories, component 3D models in the whole building, landscape or part as per the attribute values; synchronous display of 3D models and attribute information; conditional editing and retrieval according to attribute information; and attribute information input, and annex information uploading.

\section{CONCLUSION}

The "Re-relic" open scientific research platform provided the background of this paper, which analyzed the selection of the "proper technology" to improve cultural heritage digitalization efficiency and promote the retrieval of profound research through digitalization achievements. Based on the experience drawn from the "Re-Yuanmignyuan" project, and referring to a number of fundamental research files and analysis of restoration achievements and characteristics of the modularization of official building in the Qing dynasty, the QDIGACL was established and a four-step theoretical system about heritage digitalization was established. The four components are: fundamental research, restoration design, scene fabrication, and maintenance and upgrading into the mode which integrates traditional research with virtual reconstruction. In the latest round of "Re-Yuanmingyuan" projects, the concept of a component library was introduced, which testifies to the reasonableness and feasibility of this system. This work lays the foundation for the establishment of a more refined 3D model component library system in the future, and is of great significance for further improvements in cultural heritage research and protection as well as the heritage digitalization process. 


\section{REFERENCES}

K.E. Larsen, 1994. Nara Document on Authenticity, Japan.

1964. International Charter for the Conservation and Restoration of Monuments and Sites, Venice.

Yan He, 2014a. Concept and Practice about "Re-relic". Selected Proceedings of the $2^{\text {nd }}$ International Symposium on Cultural Heritage Conservation and Digitization, Shanghai, China, pp. 18-32.

Chuang Sun, Jin Shang, 2014a. Chinese Wooden Building Virtual Reconstruction Accuracy Evaluation Practic. Selected Proceedings of the $2^{\text {nd }}$ International Symposium on Cultural Heritage Conservation and Digitization, Shanghai, China, pp. 94-105.

Sanyuan Tang. 2012. Study about Parameterized 3D Component Library of Ancient Buildings in Ming and Qing Dynasty, Xi'an University of Architecture and Technology.

Engineering Department of Qing Dynasty, 1734. Gongcheng Zuofa Zeli.

Sicheng Liang, 2006. Construction Codes in Qing Dynasty, Beijing, China.

Sicheng Liang, 2006. Illustration of Gongcheng Zuofa Zeli, Beijing, China. 